\title{
CRITCA REVENW \\ A dream for pregnant mothers and newborn babies in rural India
}

\author{
Ramchandra Goyal ${ }^{1}$, \\ ${ }^{1}$ Jawaharlal Nehru Medical College-Datta Meghe Institute of Medical Sciences (Deemed \\ University), Wardha, Maharashtra 442005, India
}

Keywords:

JSSK

Pregnant women

Newborn babies

Free-referral transport services

Utilisation

Availability

Received: 30 May 2014

Accepted: 29 July 2015

Published: 15 October 2015

\begin{abstract}
In India, about 67,000 women have died every year due to pregnancy-related complications. Still, $25 \%$ of pregnant women hesitate to access health facilities due to high out-of-pocket expenses on medical care and transport required to take them from their home to health facilities. To investigate its performance, the awareness, availability, and utilization of committed referral transport services for pregnant women and sick newborns are assessed at selected public health facilities. In particular, these indicators are observed through a community and facility-based cross-sectional study conducted during 2012-2013 at two Primary Health Centres (PHCs) of the district under observation. All mothers (120) having children less than six months of age are interviewed. A modified and validated questionnaire assesses the committed free referral transportation services (FRST) cost for rural communities. Besides, all health professionals from selected public health facilities are also interviewed. The results show that the overall awareness over FRTS among participants is at $44.17 \%$. Both PHC has ambulances, but none of them has a GPS installed. The utilization of these committed and free ambulance cost is as low as $28 \%$ for pregnant women and none for sick newborn from home to health institutions; $19.24 \%$ of pregnant women and 50\% of sick newborns have been assisted by FRTS from a transfer to a higher level facility for complications, while two-third pregnant women and no sick newborn have been assisted for being dropped back home. In sum, the integrated efforts are required to maximize the utilization of committed FRTS costs for accessing healthcare and reducing maternal and newborn morbidity and mortality.
\end{abstract}

(C) 2015 The Author(s). Published by TAF Publishing.

\section{INTRODUCTION}

In India, about 67,000 women die every year due to pregnancy-related complications like haemorrhages, infections, high blood pressures, unsafe deliveries, etc. that may result in a maternal or infant mortality. In a similar

\footnotetext{
*Corresponding author: R. Goyal

E-mail:drgoyal45@gmail.com
} 
situation, about 1,300,000 infants die every year within their first year of birth. Among 900,000 newborns who die within their first four-weeks of birth (two-third of the infant deaths), about 700,000 (75\%) die within the first week, in which a majority of these 12 die during the first two13 days after birth. Therefore, the first 28-days of infancy period is critical to save children. In fact, both maternal and infant deaths are possible to reduce by ensuring a timely access to quality services, either essential or emergency, in terms of public health facilities without any excessive burden of out-of-pocket expenses [1]. However, about 25\% pregnant women in rural India are currently hesitate to access health facilities. Important factors affecting their access include a high out-of-pocket expenses on transport required to take them from home to health facilities, to a more advanced health facility in case if being referred further, and for going back from the health institution to their home [1]. To solve the problem, the Government of India has launched the Mother-Children Protection Programme (Janani-Shishu Suraksha Karyakram - JSSK) to ensure that each and every pregnant woman and sick neonates (aged up to 30 days) gets timely accesses to healthcare services, including free transportation services [1]. JSSK is first implemented in September 2011 in the Wardha district, while the current evaluation of JSSK has never been done at any place within the Vidarbha region, particularly in the Wardha district. Hence, the current study aims to observe the implementation status (availability and utilisation) of JSSK in terms of provision for free referral transport services (FRTS) at selected government health facilities within the Wardha district, Maharashtra.

\section{Objectives}

1. To assess awareness of FRTS among pregnant women at selected public health facilities.

2. To find out the availability and utilisation of FRST for pregnant women and sick newborns at selected public health facilities within the area under observation.

3. To suggest measures for improving its availability and utilisation under JSSK at selected public health facilities.

\section{MATERIALS AND METHOD}

Wardha is a district located at the eastern part of Maharashtra with a total population of 1,300,774 inhabitants (Census 2011) [2] in eight blocks. Looking at a cross-sectional study conducted between September 2012 to August 2013 at Two Primary Health Centres (PHCs), it has one of the best performing and one of least performing JSSK services based on reports by the District Health Office over two blocks, i.e. Deoli and Wardha block. All mothers (120) having children aged less than six months (deliver between September 2012 to February 2013) and public health professionals at selected Government Health Facilities are included in the study. A multi-stage simple random sampling method is taken. Information are collected by faceto-face interviews using a third-party validated, modified and pre-tested set of questionnaires (JSSK Guidelines) in local language. It is taken after obtaining a set of informed written consents from all involved mothers and health professionals. The information obtained from mothers include socio- 
demographic, awareness, and the availability \& utilisation of FRTS provided under JSSK. The information from internal JSSK service providers include

female health workers at JSSK sub-centres, medical officers at JSSKPrimaryHealth Centres, medical superintendents at JSSK Rural Hospital, civil surgeons at JSSK DH, Taluka health officers at Taluka Health Office and District Nodal Officer (JSSK, RCH officers) as per guidelines for JSSK. Secondary data are gathered from available reports and records at health facilities regarding the availability and utilisation of FRTS under the JSSK for verifying primary data. Besides, a written permission from the District Health Officer is obtained. The study protocol is approved by the Institutional Ethics Committee. A descriptive analysis is taken over gathered data, while Chisquare test and Z-test are taken with a significance level ( $p$-value) is set at lower than 0.05 .

\section{RESULTS}

This study is conducted at two blocks within Wardha district wherein beneficiaries of JSSK and JSSK service providers are being observed.

\section{JSSK Beneficiaries (Mothers)}

Socio-demographic profile of participants (mothers) discovers that most of them are within $20-24$ years old (68.33\%), which is followed by $25-29$ years $(23.33 \%)$. In fact, housewives cover a majority (83.07\%). It is followed by farm labours $(12.05 \%)$ and self-employed $(4.88 \%)$. Literacy rate is very high (98\%). However, education with up-to intermediate level is high $(63.65 \%)$ at PHC Nachangaon under Deoli block as compared to PHC Talegaon (Ta) under

TABLE 1. Socio-demographic profile of participants involved in the study

\begin{tabular}{|c|c|c|c|c|c|c|c|}
\hline \multirow{2}{*}{ Particulars } & & \multicolumn{2}{|c|}{ Block A } & \multicolumn{2}{|c|}{ Block B } & \multirow{2}{*}{$\begin{array}{l}\text { Total } \\
\text { No. }\end{array}$} & \multirow{2}{*}{$\begin{array}{l}\text { study } \\
\%\end{array}$} \\
\hline & & No. & $\%$ & No. & $\%$ & & \\
\hline \multirow{4}{*}{$\begin{array}{l}\text { Age in } \\
\text { years }\end{array}$} & $15-19$ & 0 & 0 & 3 & 5.55 & 3 & 2.77 \\
\hline & $20-24$ & 47 & 71.21 & 35 & 64.81 & 82 & 68.03 \\
\hline & $25-29$ & 13 & 19.69 & 15 & 27.77 & 28 & 23.73 \\
\hline & $30-34$ & 6 & 9.09 & 1 & 1.85 & 7 & 5.47 \\
\hline \multirow{2}{*}{$\begin{array}{l}\text { Occupatio } \\
\mathrm{n}\end{array}$} & Housewives & 51 & 77.27 & 48 & 88.88 & 99 & 83.07 \\
\hline & $\begin{array}{l}\text { Farm labourer } \\
\text { Self employed }\end{array}$ & $\begin{array}{l}11 \\
4\end{array}$ & $\begin{array}{l}16.66 \\
6.06\end{array}$ & $\begin{array}{l}4 \\
2\end{array}$ & $\begin{array}{l}7.40 \\
3.70\end{array}$ & $\begin{array}{l}15 \\
6\end{array}$ & $\begin{array}{l}12.05 \\
4.88\end{array}$ \\
\hline \multirow{6}{*}{ Education } & Illiterate & 0 & 0 & 1 & 1.85 & 1 & 0.925 \\
\hline & Primary school & 0 & 0 & & & & \\
\hline & Middle school & 3 & 4.54 & & & & \\
\hline & High school & 18 & 27.27 & & & & \\
\hline & Intermediate & 42 & 63.63 & & & & \\
\hline & Graduation \& above & 3 & 4.54 & 2 & 3.70 & 5 & 4.12 \\
\hline \multirow{5}{*}{$\begin{array}{l}\text { Socio- } \\
\text { economic } \\
\text { status** }\end{array}$} & I & 0 & 0 & 0 & 0 & 0 & \\
\hline & II & 36 & 54.54 & 18 & 33.33 & 54 & 43.93 \\
\hline & III & 22 & 33.33 & 22 & 40.74 & 44 & 37.03 \\
\hline & IV & 8 & 12.12 & 14 & 25.92 & 22 & 19.05 \\
\hline & V & 0 & 0 & 0 & 0 & 0 & 0 \\
\hline
\end{tabular}

Notes: *Tailor, Shop caretaker, tuitions at home, child caretaker.

** Socio-economic status as per Modified B.G. Prasad classification (2013)

Total study participants $=$ Block-A + Block $-B$ 
Wardha block (18.51\%) at below 0.001 p-value (significance level). Then, none belongs to socio-economic status I and V (Table 1). Awareness about FRTS under JSSK. All health professionals (100\%) have been aware of free entitlements for pregnant women and sick newborns (aged up-to 30 days). This study shows the awareness of FRTS among study participants before or at the time of delivery is $57.58 \%$ at PHC Nachangaon in Deoli block, as compared to $27.77 \%$ at PHC Talegaon (Ta) in Wardha block. The findings are statistically significant $(\mathrm{p}<0.001)$.

TABLE 2. Utilization of free referral transport services (FRTS) by the study participants (mothers)

\begin{tabular}{|c|c|c|c|c|c|c|c|}
\hline \multirow[t]{2}{*}{ Particulars } & & \multicolumn{2}{|c|}{$\begin{array}{l}\text { PHC } \\
\text { Nachangaon } \\
(n=66)\end{array}$} & \multicolumn{2}{|c|}{$\begin{array}{l}\text { PHC } \\
\text { Talegaon (Ta) } \\
(n=54)\end{array}$} & \multicolumn{2}{|c|}{$\begin{array}{l}\text { Total } \\
(n=120)\end{array}$} \\
\hline & & No. & $\%$ & No. & $\%$ & No. & $\%$ \\
\hline \multirow[t]{3}{*}{ Awareness * } & Yes & 38 & 57.58 & 15 & 27.77 & 53 & 44.17 \\
\hline & No & 28 & 42.42 & 39 & 72.23 & 67 & 55.83 \\
\hline & & \multicolumn{2}{|c|}{$\mathrm{n}=38$} & \multicolumn{2}{|c|}{$\mathrm{n}=15$} & \multicolumn{2}{|c|}{$n=53$} \\
\hline \multirow[t]{3}{*}{ Demanded transport for referral } & Yes & 32 & 84.21 & 15 & 100.00 & 47 & 88.68 \\
\hline & No & 06 & 15.78 & 00 & 0 & 06 & 11.32 \\
\hline & & \multicolumn{2}{|c|}{$\mathrm{n}=32$} & \multicolumn{2}{|c|}{$\mathrm{n}=15$} & \multicolumn{2}{|c|}{$\mathrm{n}=47$} \\
\hline \multirow{6}{*}{$\begin{array}{l}\text { Pick } \\
\text { facility } \\
\text { availed } \\
\text { mother }\end{array}$} & Yes & 09 & 28.12 & 04 & 26.66 & 13 & 27.65 \\
\hline & No & 23 & 71.88 & 11 & 73.34 & 34 & 72.35 \\
\hline & & \multicolumn{2}{|c|}{$\mathrm{n}=16$} & \multicolumn{2}{|c|}{$\mathrm{n}=10$} & \multicolumn{2}{|c|}{$\mathrm{n}=\mathbf{2 6} \neq$} \\
\hline & Yes & 03 & 18.75 & 02 & 20.00 & 05 & 19.24 \\
\hline & No & 13 & 81.25 & 08 & 80.00 & 21 & 80.76 \\
\hline & & \multicolumn{2}{|c|}{$n=66$} & \multicolumn{2}{|c|}{$\mathrm{n}=54$} & \multicolumn{2}{|c|}{$n=120$} \\
\hline \multirow{3}{*}{$\begin{array}{l}\text { Drop back to home * } \\
\text { (mothers) }\end{array}$} & Yes & 58 & 87.87 & 21 & 38.88 & 79 & 65.83 \\
\hline & No & 08 & 12.13 & 33 & 61.12 & 41 & 34.17 \\
\hline & & \multicolumn{2}{|c|}{$\mathrm{n}=32$} & \multicolumn{2}{|c|}{$n=15$} & \multicolumn{2}{|c|}{$n=47$} \\
\hline \multirow{6}{*}{\begin{tabular}{lrl}
$\begin{array}{l}\text { Pick } \\
\text { facility } \\
\text { availed }\end{array}$ & by & $\begin{array}{l}\text { From } \\
\text { institution }\end{array}$ \\
\cline { 3 - 3 } sick & & Transfer to \\
newborns & $\begin{array}{l}\text { facility for cor } \\
\text { fing }\end{array}$
\end{tabular}} & Yes & 0 & 0 & 0 & 0 & 0 & 0 \\
\hline & No & 32 & 100.00 & 15 & 100.00 & 47 & 100.00 \\
\hline & & \multicolumn{2}{|c|}{$n=04$} & \multicolumn{2}{|c|}{$n=04$} & \multicolumn{2}{|c|}{$\mathrm{n}=08 \neq$} \\
\hline & Yes & 02 & 50.00 & 02 & 50.00 & 04 & 50.00 \\
\hline & No & 02 & 50.00 & 02 & 50.00 & 04 & 50.00 \\
\hline & & \multicolumn{2}{|c|}{$\mathrm{n}=32$} & \multicolumn{2}{|c|}{$\mathrm{n}=15$} & \multicolumn{2}{|c|}{$n=47$} \\
\hline Drop back to home & Yes & 0 & 0 & 0 & 0 & 0 & 0 \\
\hline (Sick newborns) & No & 32 & 100.00 & 15 & 100.00 & 47 & 100.00 \\
\hline & & $\mathrm{n}=66$ & & $\mathrm{n}=5$ & & $\mathrm{n}=1$ & \\
\hline Paid for the transport* & Yes & 16 & 24.24 & 41 & 75.92 & 57 & 47.50 \\
\hline & No & 50 & 75.76 & 13 & 24.08 & 63 & 52.50 \\
\hline & & $n=16$ & & $n=4$ & & $\mathbf{n}=5$ & \\
\hline Amount re-imbursed & Yes & 00 & 00 & 00 & 00 & 00 & 00 \\
\hline & No & 16 & 100.00 & 41 & 100.00 & 57 & 100.00 \\
\hline
\end{tabular}

Notes: $\mathrm{n}$ number of study participants (Beneficiaries)

$\neq$ number of complicated cases

$* \mathrm{p}<0.001$ (highly significant) 
(Ta) in Wardha block. In fact, the difference is statistically stated as highly significant $(p<0.001)$. Nearly 50\% sick newborns have been assisted by FRTS for transfers to higher level facilities in both blocks, in which none has received FRTS for home-to hospital transports and drop-back home. Majority (75.92\%) at PHC Talegaon (Ta) in Wardha block pay for the service as compared to 16 $(24.24 \%)$ at PHC Nachangaon in Deoli block, which is highly significant ( $p<$ 0.001). Money reimbursement is in fact not given to study participants who have paid charges for referral transport services.

\section{JSSK Service Providers}

A total of 16 health professionals has been aware of FRTS for pregnant women and sick newborns (aged up-to 30 days).

FRTS under JSSK are available in Wardha District as reported by JSSK service providers and beneficiaries (mothers). JSSK service providers in the observed area report that there is a total of 37 ambulances /referral district vehicles in the district. None of them has GPS installed. The district's call centre number is 102. In fact, no EMRT/EMTS, PPP and other ambulances /referral vehicles are used for FRTS in the district. Occasionally, JSSK service providers hire private vehicles.

As reported by JSSK service providers at selected public health facilities, about $47.00-95.46 \%$ pregnant women and $10.00-12.54 \%$ sick newborns have experienced FRTS for home-to-hospital transports. Besides, 20.00-37.78\% pregnant women and $40.00-55.42 \%$ sick newborns have received FRTS for transfer to higher level facilities. Then, $87.75-99.46 \%$ pregnant women and 10.00-64.16\% sick newborns have been assisted by FRTS for a drop-back home. However, the current study reveals facts in which only $27.65 \%$ pregnant women and no sick newborn have been experiencing FRTS for home-to-hospital transports, while $19.24 \%$ pregnant women and 50\% sick newborns have received FRTS for transfers to higher-level health facilities, and 65.83\% pregnant women and no sick newborn have been assisted by FRTS for a drop118

back home.

\section{DISCUSSION}

\section{Socio-demographic profile}

The profile reveals that most participants $(68.33 \%)$ belong to the age group of 20-24 years, while $83.07 \%$ are housewives and literacy rate is at $98 \%$. In fact, UNICEF's coverage evaluation survey report for India (2010) has reported a figure of 75.8\% [3]. However, literature searches for JSSK in India do not show any community-based studies for socio-demographic profile.

\section{Awareness about FRTS under JSSK}

All health professionals (100\%) have been aware of free entitlements for pregnant women and sick newborns (aged up-to 30 days). This study shows the awareness of FRTS among study participants before or at the time of delivery is $57.58 \%$ at PHC Nachangaon in Deoli block, as compared to $27.77 \%$ at PHC Talegaon (Ta) in Wardha block. The findings are statistically significant ( $\mathrm{p}<$ 0.001). The poor JSSK awareness at Wardha block may have been due to an inadequate information dissemination on the services. Rathore [3] has observed 
a good awareness of free entitlements among pregnant women. However, a low awareness is observed by Baruah [2] at Punjab, Haryana, UP and Bihar.

\section{Displays of free entitlements}

JSSK service providers in selected public health facilities have reported that free entitlements are displayed at all health facilities in Wardha district. Similar findings are reported to occur between 2011-2013 by Indian Institute of Health Management and Research (IIHMR) [5], Baruah [4], Bhushan [6], the National Rural Health Mission (NRHM) at West Bengal [7], NRHM at Nagaland [8], the Department of Health \& Family Welfare at Meghalaya [9], the National Health System Resources Centre (NHSRC) [10], NRHM at Uttarakhand [11], the Ministry of Health \& Family Welfare at Maharashtra [12] and Kumar [13].

Although all health functionaries have reported the display 148 of free entitlements; however, it is observed that $50 \%$ of sub-centres being observed do not display the free entitlements charts. In fact, mothers from the area also report that none of the sub-centres at PHC Talegaon (Ta) in Wardha block has displayed free entitlements.

\section{The availability of FRTS provided under JSSK}

As reported by district health officials, there is a total of 37 ambulances/referral district vehicles within the district for FRTS. In fact, none of them has GPS installed. A similar finding is reported by the Ministry of Health \& Family Welfare-Maharashtra [12], the Department of Health \& Family Welfare Meghalaya [9], the NRHM-West Bengal [7] and the NHSRC [10]. Besides, the NRHM-Nagaland [8] has reported that 66 state-owned referral vehicles have GPS installed.

Furthermore, EMRT/EMTS, PPP referral vehicles are utilised. Meanwhile, similar findings are reported by the NRHM-Nagaland [8], the Department of Health \& Family Welfare - Meghalaya [9], and the NRHM - West Bengal [7]. An exception is found for the report by NRHM-Uttarakhand [11], which shows that no EMRT/EMTS referral vehicle is utilised.

\section{The utilisation of FRTS}

The current study reveals that nearly $28 \%$ pregnant women and none of the sick newborn have experienced the services for home-to-health institutions transports, while $19.24 \%$ pregnant women and about 50\% sick newborns have been receiving FRTS for transfers to higher-level health facilities for complications. Then, $65.83 \%$ pregnant women and no sick newborn have been assisted by a free drop-back home transport facility within the area under observation. The utilisation of drop-back home transport facility is found as being caused by information dissemination, in which information on FRTS is given at the time of delivery or immediately after delivery. Meanwhile, the reason for a low utilisation is poor awareness. The State Institute of Health \& Family Welfare (SIHFW) - Jaipur [14] has found that nearly 59.5\% pregnant women and $1.79 \%$ sick newborns have received FRTS forhome-to-health institution transports, while $71.26 \%$ pregnant women and $3.06 \%$ sick newborns have experienced the services for health institution-to-home transports. Rathore [4] has concluded that there is an $88 \%$ achievement in the provision of referral transport facility for pregnant women. 
Furthermore, IIHMR [5] has concluded that there is an $88 \%$ achievement rate in the provision of drop-back transport facility for pregnant women (hospital-tohome). A report by the Ministry of Health \& Family Welfare - Maharashtra [12] has stated that $18.34 \%$ pregnant women and delivered mothers and $1 \%$ sick neonates have been assisted by FRTS for home-to-hospital transports, while $16.21 \%$ pregnant women and delivered mother and $1.8 \%$ sick neonates have been receiving FRTS for basic-to advance health institutions. Then, 40\% pregnant women and delivered mothers and $4 \%$ sick neonates have experienced FRTS for hospital-to-home transports. NHSRC [10] has found that FRTS vehicles have been taken by $50 \%$ of pregnant women in Orissa. In fact, transports for pregnant women from home to hospital have been properly conducted at Bihar, Andra-Pradesh, Gujarat, Haryana, and Maharashtra. However, drop-back transports are poor at all the places, which may have largely occurred due to a poor awareness.

\section{CONCLUSION}

Despite having JSSK started in the Wardha district since September 2011, the awareness and utilisation of FRTS have in fact not been taken to 198 its fullest potential. In particular, gaps are found between reported figures by health professionals and actual responses by participants (mothers). It may have been resulted due to a poor

\section{RECOMMENDATIONS}

After a careful analysis, these following recommendations are proposed:

1. Awareness at community level should be enhanced through a wider dissemination of IEC materials in local language by providing, for example, awareness camps or various print and electronic advertisements.

2. All free entitlements under JSSK need to be clearly displayed at all healthcare facilities.

3. Awareness at facility level should be increased by organising workshops for enhancing the sensitivity of all healthcare professionals.

4. FRTS with GPS facility are required for all at the right place and time.

5. A public-private partnership may possibly work for providing the transports.

6. There should be a high-level of co-ordination and frequent communication within the hierarchy of healthcare providers for a better implementation.

7. Administrators and service providers should provide supportive and supervisory visits, feedbacks, reviews and follow-up, more frequently.

8. Reviews should be taken periodically for assessing the implementation status.

\section{LIMITATIONS}

In fact, the current study cannot be extended to all 8 blocks, 2 sub district hospitals, 8 rural hospitals, 27 primary health centres and 180 sub-centres due to some time related constraints.

\section{REFERENCES}

1. Ministry of Health and Family Welfare. Guidelines for Janani-Shishu Suraksha Karyakram (JSSK) . New Delhi, IN: National Rural Health Mission, Maternal Health Division, the Government of India; 2001 Jun. 
2. Baruah J. Janani-Shishu Suraksha Karyakram: Progress and challenges (10 States). New Delhi, IN: Public Health Planning, National Health Systems Resource Centre, the Government of India; 2012.

3. UNICEF, the Government of India. Coverage evaluation survey 2009: All India report 2010. New Delhi, IN: UNICEF; 2009. p68, p73. Available from: www.unicef.org/india/health.html

4. Rathore G. Janani-Shishu Suraksha Karyakram: Rajasthan experience. Rajasthan, IN: National Rural Health Mission; 2012.

5. Indian Institute of Health Management and Research (IIHMR). Janani Shishu Suraksha Karyakram: Report. Rajasthan, IN: IIHMR; 2011 Oct to 2012 Mar.

6. Bhushan H. Janani-Shishu Suraksha Karyakram: Review. New Delhi, IN: Ministry of Health and Family Welfare, the Government of India; 2012 Sep.

7. National Rural Health Mission (NRHM) West Bengal. Implementation status of JSSK Report . West Bengal, IN: the Government of West Bengal; 2012. Available from: www.wbhealth.gov.in/NRHM/pdf/JSSKReport

8. National Rural Health Mission (NRHM) Nagaland. Implementation status of JSSK Report . Nagaland, IN: the Government of Nagaland; 2012. Available from: www.wbhealth.gov.in/NRHM/pdf/JSSKReport

9. Department of Health \& Family Welfare-Meghalaya. Implementation status of JSSK Report . Meghalaya, IN: National Rural Health Mission, the Government of Meghalaya; 2012. Available from: meghealth.nic.in/NRHM/pdf/JSSK Report

10. National Health System Resource Centre (NHSRC). Janani-Shishu Suraksha Karyakram: Review. New Delhi, IN: NHRSC; 2012-2013 Q1.

11. National Rural Health Mission (NRHM) Uttarakhand. Implementation status of JSSK (District level) Report, Uttarakhand, IN: Tehri Garhwal Uttarakhand, the Government of Uttarakhand; 2013.

12. Ministry of Health \& Family Welfare. Implementation status of JSSK Report . Maharashtra, IN: National Rural Health Mission; 2011-2012. Available from: www.nrhm.maharashtra.gov.in/schjssk.html

13. Kumar R. Maternal health: Review meeting of state mission directors: Janani-Shishu Suraksha Karyakram. New Delhi, IN: Ministry of Health and Family Welfare, the Government of India, 2012 Oct.

14. State Institute of Health \& Family Welfare (SIHFW). Implementation status of JSSK Report . Jaipur, IN: SIHFW; 2012 Sep to 2013 Jul. Available from: www.sihfwrajasthan.com/ppt/full/JSSY.pdf

— This article does not have any appendix. - 